\title{
Social Bonding dalam Pengelolaan Hutan Rakyat: Upaya Menuju Masyarakat Hutan yang Sejahtera
}

\author{
Khabib Bima Setiyawan ${ }^{1}$ \\ Universitas Sebelas Maret, Surakarta - Indonesia
}

\begin{abstract}
The forest is the source of livelihood of the community around it, forest sustainbility management become important thing to do to ensure the sustainbility of the forest. This research discusses about forest management strategies in the Berjo village, in which consist of three different institutions, they are Taman Hutan Raya (Tahura), Perusahaan Hutan Negara Indonesia (Perhutani), and Lembaga Masyarakat Desa Hutan (LMDH). the aim of this research is to find out the forest management strategies, methode in this research is qualitaive with case studies approach, this research conducted in the village of Berjo, Karangayar city. Purposive sampling is used to select the respondents. Data collection is done by observation, interviews, and documentation. The analysis of the data using the in interactive functional analysis and validation of data using triangulation of sources. The results showed that forest management is achieved by collaboration among Government and non government institutions with their Sosial Bonding Capital which allows for interaction in sharing knowledge as well as glue relations between groups. Social Bonding is owned by LMDH and Tahura are on the intermediate level which means they obey formal but on the other hand they approach at the level of values, culture, and perception. While the relationship between the LMDH (a unit of BUMN) and Tahura (units of goverment departmen) are on the level of social capital that embraced a formal value corresponding their jobs desk which are conservation and production of the forest. LMDH along with Perhutani in forest management through partnership relationship. They work togehter in the safeguarding of forests and open tourist attraction. Whereas in the greening of the forest, the Perhutani, the LMDH Tahura and do reforestation.
\end{abstract}

Hutan merupakan sumber penghidupan masyarakat disekitarnya, maka perlu adanya upaya mengelola hutan rakyat tetap agar lestari. Penelitian ini membahas mengenai strategi pengelolaan hutan rakyat di Desa Berjo, dalam pengelolaannya terdapat tiga unsur yaitu Taman Hutan Raya (Tahura), Perusahaan Hutan Negara Indonesia (Perhutani), dan Lembaga Masyarakat Desa Hutan (LMDH). Penelitian kualitatif dengan pendekatan studi kasus ini bertujuan untuk mengetahui strategi pengelolaan hutan rakyat. Pemilihan informan menggunakan purposive. Pengumpulan data dilakukan dengan observasi, wawancara, dan dokumentasi. Analisis data menggunakan analisis interaktif fungsional dan divaliditas menggunakan triangulasi sumber. Hasil penelitian menunjukkan bahwa Pengelolaan hutan rakyat di Berjo tercapai dengan kolaborasi antar lembaga pemerintah maupun non pemerintah dengan modal sosial berupa kedekatan (social bonding) yang memungkinkan adanya interaksi dalam membagi pengetahuan sekaligus sebagai perekat hubungan antar kelompok Social Bonding yang oleh LMDH dan Tahura tergolong dalam level pertengahan, menganut aturan formal mendekati pada level nilai, kultur, dan persepsi. Sedangkan hubungan antara Perhutani (satuan BUMN) dan Tahura (Satuan Dinas) berada pada level modal sosial yang menganut nilai-nilai formal sesuai tupoksi konservasi dan produksi. LMDH bersama Perhutani melakukan

${ }^{1}$ Korespondensi: Khabib Bima Setiyawan (lkhabibbima20@yahoo.co.id), Program Studi Sosiologi, Fakultas Ilmu Sosial dan Politik Universitas Sebelas Maret, Jl. Ir. Sutami No.36A, Kentingan, Kota Surakarta 57126 - Indonesia. 
kerjasama dalam pengelolaan hutan melalui hubungan mitra dalam pengamanan hutan dan membuka objek wisata. Sedangkan dalam penghijauan hutan, Perhutani, LMDH dan Tahura melakukan reboisasi.

Keywords: forest; management; social capital; social bonding

\section{Pendahuluan}

Indonesia dijuluki sebagai negara maritim dan negara hutan tropis (Nugroho 2010). Sebagai sumber plasma nutfah, hutan memiliki arti penting terutama bagi masyarakat di sekitarnya yang memanfaatkan hasil hutan untuk dijadikan pemenuh kebutuhan sehari-hari.

Hutan rakyat sebagai salah satu sumber pendapatan negara belum dikelola dengan optimal. Pembangunan hutan rakyat di sekitar kawasan hutan lindung mempunyai fungsi strategis untuk meningkatkan pendapatan masyarakat sekitar hutan dan mengurangi ketergantungan masyarakat terhadap sumber daya hutan yang potensinya terus menurun, terutama dengan munculnya hutan-hutan kritis (Handoko, Yudilastiantoro, dan Sukito 2012).

Pengelolaan yang mengedepankan tujuan kolektif antara pemerintah dan masyarakat menjadi penting demi menjaga kelestarian hutan dimasa kini dan masa yang akan datang. Hutan rakyat perlu dikembangkan melalui penyediaan bibit bagi hutan yang baru dipanen. Di samping itu, bagi perusahaan dan rakyat yang memanfaatkan hasil hutan perlu melakukan pengamanan kayu dan keharusan untuk melakukan reboisasi. Seluruh pengelolaan hutan tersebut harus diarahkan untuk mencegah kerusakan dan menjaga kelestar ian hutan (Hanani, Ibrahim, dan Purnomo 2003).

Desa Berjo sebagai salah satu yang berada di Kecamatan Ngargoyoso Kabupaten Karanganyar Provinsi Jawa Tengah merupakan desa dengan sebagian besar wilayahnya adalah hutan yang berada di bawah Gunung Lawu. Dengan adanya Sumber Daya Alam (SDA) tersebut, Desa Berjo berupaya untuk mengelola hutan agar dapat dimanfaatkan secara efektif dan efisien demi kesejahteraan masyarakat sekitar. Dalam Pengelolaannya, terdapat tiga pihak yaitu Taman Hutan Raya (Tahura), Perusahaan Hutan Negara Indonesia (Perhutani), dan Lembaga Masyarakat Desa Hutan (LMDH). Ketiganya memiliki tupoksi kerja masing-masing yang terintegrasi berdasarkan tujuan untuk mengoptimalkan pengelolaan hutan agar tetap lestari. Tidak dipungkiri juga kegitanya melakukan kolaborasi dalam mengelola hutan sehingga memungkinkan adanya interaksi yang terbentuk akibat adanya modal sosial.

Artikel ini mengkaji mengenai pengelolaan hutan yang melibatkan LMDH, Perhutani, dan Tahura. Untuk mengkaji ini penulis berusaha menjawab pertanya berikut, yaitu: bagaiamana pengelolaan hutan tersebut mampu menjadikan masyarakat disekitarnya sejahtera? Upaya ini dilakukan dengan menggunakan teori sosiologi, yaitu analisis modal sosial dalam pengelolaan hutan tersebut.

Penelitian ini merupakan penelitian kualitatif yang berada di Desa Berjo, Kecamatan Ngargoyoso, Karanganyar, Jawa Tengah. Penelitian dilaksanakan pada bulan April-Mei 2017. Desa ini mempunyai luas wilayah 1623,865 Ha terletak di lereng Gunung Lawu. Desa Berjo memiliki topografi berupa daerah yang tinggi, berada di ketinggian $\pm 1.500 \mathrm{mdpl}$, dengan suhu udara rata - rata $\pm 22^{\circ} \mathrm{C}$ sampai dengan $32^{\circ} \mathrm{C}$ dan beriklim tropis. Sebelah utara Desa Berjo dibatasi oleh desa Girimulyo, sebelah timur dibatasi oleh hutan Lawu, sebelah selatan dibatasi oleh Kecamatan Tawangmangu, dan sebelah barat dibatasi oleh Desa Puntukrejo. 
Penelitian ini dimulai dari persiapan dalam melakukan perizinan kepada pihak terkait dalam hal ini LMDH, Perhutani, dan Tahura kemudian dilanjutkan dengan proses pengambilan data melalui observasi, wawancara dan studi dokumentasi. Dalam memilih informan, peneliti menggunakan teknik purposive yaitu dengan melakukan indepth interview untuk mendapatkan data yang mendalam. Peneliti menggunakan studi dokumentasi berupa catatan selama proses penelitian, rekaman suara, dan foto sebagai data pendukung. Setelah data terpenuhi, peneliti melakukan analisis interaktif fungsional yang berpangkal dari empat kegiatan yaitu pengumpulan data, reduksi data, penyajian data dan uji validitas data menggunakan triangulasi sumber (Miles, Huberman, dan Saldana 2014).

Lembaga Masyarakat Desa Hutan merupakan sebuah organisasi yang bertujuan meningkatkan kesejahteraan masyarakat sekitar kawasan hutan dan pelestarian hutan. Di Berjo bernama LMDH "Wana Hijau Lestari" lahir pada tahun 2001 beranggotakan masyarakat Desa Berjo, Kecamatan Ngargoyoso, Kabupaten Karanganyar.

Perhutani adalah Badan Usaha Milik Negara di Indonesia yang bertugas untuk merencanakan, mengurusi, pengusahaan dan perlindungan di wilayah kerja. Perhutani dibagi menjadi beberapa organisasi pengelola berupa Kepala Resort Pangkuan Hutan. Dalam Pengelolaan Hutan Lawu terdapat 6 Kepala Resort Pangkuan Hutan (KRPH) antara lain KRPH Gunung Bromo, KRPH Nglerak, KRPH Blumbang, KRPH Banjarsari, KRPH Telaga Dringo, dan KRPH Tambak. KRPH yang berada di Desa Berjo yaitu KRPH Tambak dengan luas wilayah sekitar $1200 \mathrm{Ha}$.

Tahura merupakan institusi di bawah Pemerintah Provinsi Jawa Tengah. Tahura Mangkunagoro I yang terletak di lereng Gunung Lawu sisi barat saat ini merupakan satu-satunya Tahura yang ada di Jawa Tengah dan satusatunya kawasan hutan konservasi yang dikelola oleh Pemerintah Daerah yang juga menjadi kebanggaan daerah. Tahura Mangkunagoro I merupakan kawasan pelestarian alam dengan luas \pm 231 ,3 ha terletak di lereng Gunung Lawu yang secara administratif pemerintahan berada di Desa Berjo, Ngargoyoso, Karanganyar, Jawa Tengah. Secara geografis terletak $111^{\circ} 8^{\prime} 13^{\prime \prime}$ -

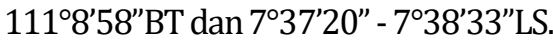

\section{Tinjauan Modal Sosial dalam Pengelolaan Hutan}

Modal sosial sebagai segala sesuatu hal yang berkaitan dengan kerja sama dalam masyarakat atau bangsa untuk mencapai kapasitas hidup yang lebih baik, ditopang oleh nilai-nilai dan norma yang menjadi unsur-unsur utamanya seperti trust (rasa saling mempercayai), ketimbalbalikan, aturan-aturan kolektif dalam suatu masyarakat atau bangsa dan sejenisnya (Hasbullah 2006). Menurut Putnam tiga dimensi sosial yang harus ada: jaringan atau hubungan sosial, norma, dan kepercayaan (Slamet 2012, 18). Dalam proses pengelolaan hutan di Desa Berjo terdapat jaringan sosial antara pihak yang terlibat dalam hal ini LMDH, Perhutani dan Tahura. Ketiganya juga memegang prinsip norma dan kepercayaan dalam tingkatan masing-masing.

Dalam modal sosial terdapat norma informal dan bukan aturan konstitusi formal, ada aktivitas relasi antar dua orang atau lebih, ada resiprositas (hubungan timbal-balik), diwujudkan hanya dalam hubungan yang sangat erat (pertemanan) bukan hubungan formal, dan untuk pencapaian tujuan. Fukuyama membandingkan karakteristik masyarakat Asia Tenggara yang tingkat hubungan sosialnya tinggi dengan masyarakat Eropa dan Amerika yang cenderung individualistis (Rais 2009).

Modal sosial juga inheren dalam struktur relasi antar individu. Struktur relasi dan jaringan inilah yang menciptakan berbagai ragam kewajiban sosial, menciptakan saling percaya, membawa saluran informasi dan menetapkan norma-norma 
dan sanksi sosial bagi para anggotanya. Dalam hal ini modal sosial berperspektif hubungan dengan sesama (individu) sebagai unit analisisnya. Sementara itu, modal sosial juga mencakup perspektif yang lebih luas yakni segala sesuatu yang membuat masyarakat bersekutu untuk mencapai tujuan bersama atas dasar kebersamaan, dan di dalamnya diikat oleh nilai-nilai dan norma-norma yang tumbuh dan dipatuhi.

\section{Social Bonding dalam Pengelolaan Hutan}

Dalam konteks keeratannya dan keberagaman, modal sosial terklasifikasi menjadi tiga jenis modal sosial, yaitu: (i) bonding, (ii) bridging, dan (iii) linking. Bonding social capital adalah ikatan perasaan diantara orang-orang yang ada dalam situasi yang sama, semisal ikatan keluarga, kawan karib, dan ketetanggaan). Bridging social capital adalah ikatan modal sosial yang lebih luas dan lebih longgar, seperti pertemanan dan rekan kerja) (Woolcock 2001). Linking social capital adalah ikatan modal sosial yang angggotanya dari beragam latar belakang, semisal satu komunitas dengan pihak luar, dan ikatan yang demikian akan memungkinkan kita bisa mengakses beragam sumber untuk kepentingan komunitas (Field 2008, 46).

Modal sosial yang lebih kuat dalam pengelolaan hutan yaitu modal sosial bonding karena menurut penuturan ketiga pihak (yaitu: LMDH, $\mathrm{RPH}$, dan Perhutani) yang terlibat dalam pengelolaan hutan di Desa Berjo kedekatan antara ketiganya dalam hal jarak tempat dan hubungan sosial merupakan faktor yang sangat mendukung dalam koordinasi. Modal social linking lebih pada hubungan dan tanggungjawab antar unsur pengelola kepada lembaga secara hirarki. Adapun sosial bridging dalam pengelolaan hutan belum memungkinkan adanya pihak luar untuk bergabung dalam pengelolaan hutan karena selama ini hutan masih dikelola secara mandiri. Berikut merupakan identifikasi social bonding dalam pengelolaan hutan di Desa Berjo.

Tabel 1.

Identifikasi Modal Sosial Bonding

\begin{tabular}{|c|c|c|}
\hline No. & Identifikasi Modal Sosial & Integrasi modal Social Bonding \\
\hline 1 & Jaringan sosial & $\begin{array}{l}\text { - Hubungan tetangga yang berdekatan antara Perhutani, Tahura, dan LMDH } \\
\text { terletak yang terletak di Dusun Tambak Desa Berjo dalam satu Resort } \\
\text { Pangkuan Hutan (RPH) Tambak }\end{array}$ \\
\hline 2 & Sistem kepercayaan & $\begin{array}{l}\text { - Sistem kepercayaan antara Perhutani dan Tahura menjalankan tugas } \\
\text { sesuai tupoksi kerja; } \\
\text { - Tahura dengan LMDH dalam upaya kerja bakti dan reboisasi hutan; dan } \\
\text { - Perhutani dengan LMDH sebagai mitra pertemanan yang menganut nilai- } \\
\text { nilai simpati, kepercayaan, dan resiprositas pada level kultural. }\end{array}$ \\
\hline 3 & Norma sosial & $\begin{array}{l}\text { - Terjalin norma sosial antara Perhutani dan LMDH sampai ke hubungan } \\
\text { pertemanan sebagai mitra melestarikan hutan dan membangun Program } \\
\text { Kerja (POKJA) dengan kepemilikan kolektif, masyarakat diperbolehkan } \\
\text { mengambil hasil rumput untuk pakan hewan ternak dan ranting kayu } \\
\text { untuk bahan bakar. }\end{array}$ \\
\hline 4 & Hubungan timbal balik & $\begin{array}{l}\text { - Hubungan resiprositas dalam membagi pengetahuan dalam FGD rutin tiap } \\
\text { bulan antara Perhutani, Tahura, dan LMDH di lingkungan warga Dusun } \\
\text { Tambak Desa Berjo. } \\
\text { - Masyarakat mengambil rumput dan ranting kayu sekaligus membantu } \\
\text { Perhutani mengamankan hutan }\end{array}$ \\
\hline
\end{tabular}

Sumber: Data primer, tahun 2017 
Dalam pengelolaan hutan, social bonding pada level kultural dianut oleh LMDH dan Perhutani sebagai mitra dalam pengelolaan hutan rakyat. Hubungan kemitraan antara kedua belah pihak bersifat kekeluargaan dan lebih memegang norma informal sesuai kultur. Kerjasama dilakukan dalam hal pengamanan hutan, penghijauan, dan pembukaan objek wisata. Kedua belah pihak merasa sudah mempunyai hubungan percaya (trust) dalam menjaga keamanan hutan, walaupun secara aturan intistusi formal menurut Peraturan Pemerintah Republik Indonesia Nomor 24 Tahun 2010 Tentang Penggunaan Kawasan Hutan, Bab I Pasal 1 (4) bahwa "Hutan lindung adalah kawasan hutan yang mempunyai fungsi pokok sebagai perlindungan sistem penyangga kehidupan untuk mengatur tata air, mencegah banjir, mengendalikan erosi, mencegah intrusi air laut, dan memelihara kesuburan tanah." Sehingga penting untuk tidak merusak ekosistem, tetapi secara norma informal terdapat kesepakatan dari nenek moyang yang sampai sekarang masih diberlaku antara Perhutani dan masyarakat (LMDH) yaitu setiap warga diberikan luas 0,25 Ha hanya untuk mengambil rumput tanpa mengubah struktur tanah. Kesepakatan tersebut menyebabkan terjadinya hubungan resiprositas antara Perhutani dan LMDH. Perhutani merasa diuntungkan dengan aktivitas rutin setiap hari oleh pengaram (sebutan bagi pengambil rumput) yang setiap hari ke huutan mengambil hasil rumput sekaligus sebagai upaya pengamanan hutan oleh masyarakat mengingat hanya terdapat 4 petugas Perhutani di Resort Pangkuan Hutan Tambak, LMDH juga diuntungkan dengan pengaram yang mengambil hasil rumput untuk memberi makan hewan ternak. Keuntungan lain yaitu menjaga pohon agar dapat menyerap air secara maksimal.

Program penghijauan dilakukan juga oleh LMDH dan Perhutani sebagai upaya menjaga kelestarian ekosistem hutan rayat di Desa Berjo secara gotong royong bekerja tanpa imbalan.

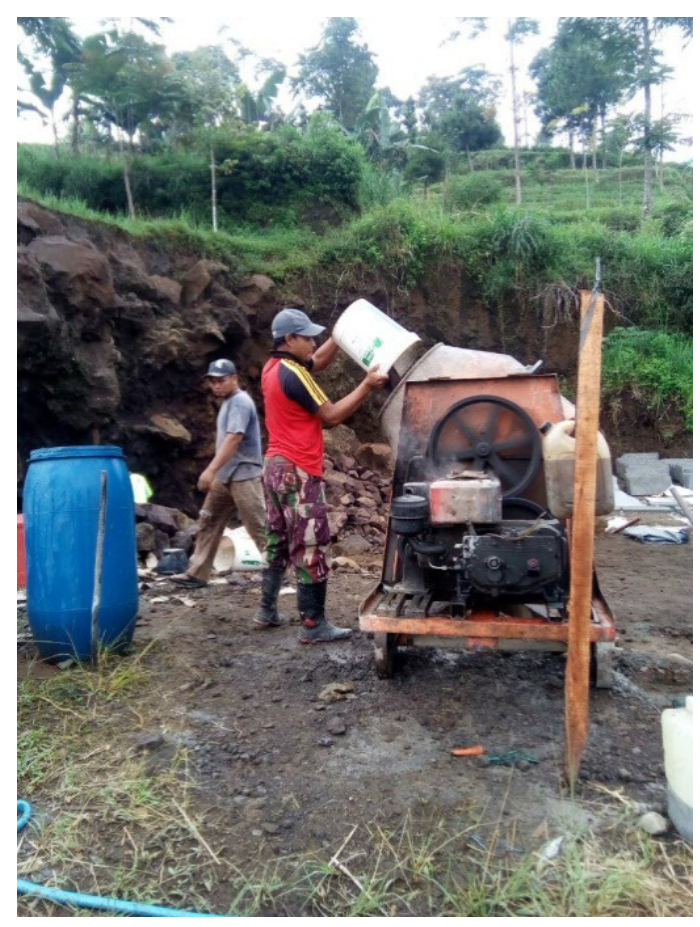

Gambar 1.

Desa Hutan (LMDH) Desa Berjo dalam pembuatan obyek wisata "Tempurung Pandang"

Pembukaan objek wisata juga menjadi Progam Kerja (POKJA) yang dilaksanakan oleh LMDH dan Perhutani, biaya operasional ditanggung bersama dan pengerjaan juga dilakukan dengan sistem kerja bakti. Upaya pembuatan POKJA tersebut sekaligus menjadi posko pemantauan oleh LMDH dan Perhutani dalam pengamanan hutan karena jalur wisata berdekatan dengan area hutan. Rasa simpati juga ditunjukkan oleh kedua belah pihak salah satunya dengan menjenguk apabila ada salah satu anggota yang sakit.

Modal sosial antara LMDH dan Perhutani yang berkembang selama ini menengarah pada terbentunya tiga level modal sosial, yakni pada level nilai, intitusi, dan mekanisme, sebagaimana tergambar pada Gambar 2. 


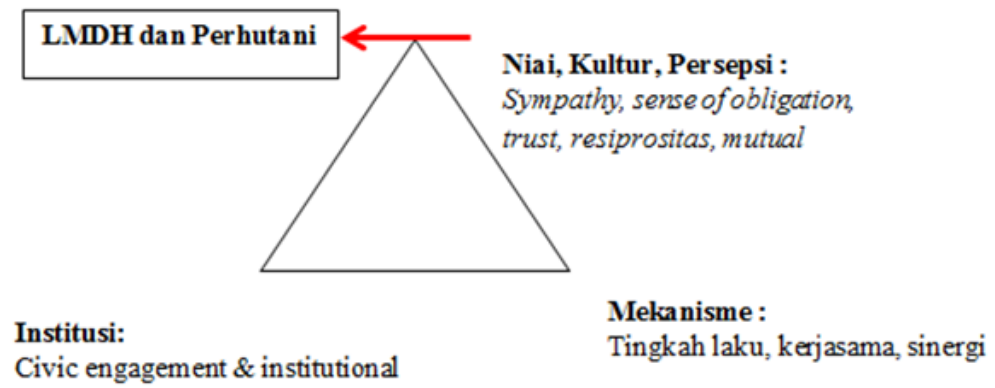

Gambar 2. Level Modal Sosial antara LMDH dan Perhutani

Diantara ketiga pihak yang mengelola hutan, level modal sosial tertinggi dimiliki oleh LMDH dan Perhutani yang memang merupakan mitra dalam melakukan tipoksi kerja yang telah dijelaskan diatas. Sedangkan Tahura sebagai Institusi Provinsi menjadi pihak yang memastikan ekosistem hutan tetap terjaga melalui upaya konservasi yang dilakukan bersama LMDH.

\section{Simpulan}

Dalam pengelolaan hutan di Desa Berjo, terdapat tiga pihak yang berkolaborasi yaitu LMDH, Perhutani, dan Tahura. LMDH sebagai mitra Perhutani melakukan kegiatan dalam pengelolaan hutan sebagai berikut: 1) Reboisasi hutan secara gotong royong. 2) Pelaksanaan program kerja pembukaan objek wisata. 4) Pengamanan hutan setiap masyarakat mengambil rumput.

Kesejahteraan masyarakat hutan dicapai melalui mitra dengan Perhutani dalam mengambil rumput untuk pakan hewan ternak dan ranting untuk bahan bakar, kegiatan ke hutan dilaksanakan hampir oleh semua masyarakat di Desa Berjo terutama di kawasan sekitar hutan. Sedangkan Tahura juga melaksanakan tupoksi dalam upaya pelestarian hutan secara konservatif dan melalui cara reboisasi. Kegita unsur pengelola hutan juga melakukan pertemuan rutin sebagai upaya koordinasi dalam pelestarian hutan secara kolektif.]

\section{Daftar Pustaka}

Field, John. 2008. Social Capital. Canada: Routledge.

Hanani, Nuhfil, Jabat Tarik Ibrahim, dan Mangku Purnomo. 2003. Strategi Pembangunan Pertanian: Sebuah Pemikiran Baru. Yogyakarta: LAPPERA Pustaka Utama.

Handoko, Cecep, C. Yudilastiantoro, dan Agus Sukito. 2012. "Identifikasi Tahapan dan Faktor-Faktor Sosial Pembangunan Hutan Rakyat di Sekitar Kawasan Hutan Lindung." Jurnal Penelitian Kehutanan Wallacea 1(2): 135.

Hasbullah, J. 2006. Sosial Kapital: Menuju Keunggulan Budaya Manusia Indonesia. Jakarta: MR-United Press.

Miles, M B, A M Huberman, dan J Saldana. 2014. Qualitative Data Analysis. California: SAGE Publications. 
Nugroho, Bramasto. 2010. "Strategi Pengembangan Ekowisata di Kabupaten Kepulauan Yapen Provinsi Papua." Jurnal Manajemen Hutan Tropika (Journal of Tropical Forest Management) 16(3): 148-54.

Rais, Rahmat. 2009. Modal Sosial Sebagai Strategi Pengembangan Madrasah. Jakarta: Litbang dan Diklat Departemen Agama.

Slamet, Yulius. 2012. Modal Sosial dan Kemiskinan. Surakarta: UNS Press.

Woolcock, Michael. 2001. "The Place of Social Capital in Understanding Social and Economic Outcome." Canadian Journal of Policy Research 2. 
JPW (Jurnal Politik Walisongo) - Vol. 1, No. 1 (2019) 